\title{
Simple things matter! How reassurance and pain management strategies can improve outcomes in physiotherapy: A case report
}

\author{
Guillaume Léonard, P.T., Ph.D. ${ }^{1,2}$, Yannick Tousignant-Laflamme, P.T., Ph.D. ${ }^{2}$ \\ Catherine Mercier, O.T., Ph.D. ${ }^{1}$ \\ ${ }^{1}$ Centre interdisciplinaire de recherche en réadaptation et en intégration sociale (CIRRIS) \\ de l'Université Laval, 585 boulevard Hamel, Québec (Québec), Canada, G1M 2S8; ${ }^{2}$ École \\ de réadaptation de l'Université de Sherbrooke, $300112^{\mathrm{e}}$ avenue Nord, Sherbrooke \\ (Québec), Canada, J1H 5N4
}

\author{
Address for correspondence \\ Guillaume Léonard \\ École de réadaptation \\ Faculté de médecine et des sciences de la santé \\ $3001,12^{\mathrm{e}}$ avenue Nord \\ Sherbrooke (Québec) \\ J1H $5 \mathrm{~N} 4$ \\ Canada
}

\section{Conflicts of Interest and Source of Funding}

Guillaume Léonard and Catherine Mercier are supported by CIHR (Canada). Catherine Mercier is also supported by NSERC (Canada) and FRSQ (Québec). Yannick TousignantLaflamme is a supported member of the Centre de recherche Clinique Etienne-Le Bel du CHUS. The authors declare no conflict of interest. 


\begin{abstract}
Psychological barriers to rehabilitation are generally seen as preexisting patient traits that clinicians are asked to evaluate and modify. In the present case report, we provide evidence that these barriers can also be involuntarily created or perpetuated by the clinician himself when too much attention is placed on physical abnormalities. Without discarding the need to treat the presumed biological source of pain, these observations remind rehabilitation professionals about the importance of displaying a confident and reassuring attitude towards pain patients in order to reduce anxiety, promote physical activity and reinforce self-management strategies.
\end{abstract}

Keywords: Pain, psychological factors, physiotherapy, rehabilitation 


\section{Introduction}

There is substantial evidence regarding risk factors for the development of persistent pain. Among the various factors identified, psychosocial factors have retained a lot of attention, and there are now significant indications which suggest that elements such as maladaptive coping behaviors and misbeliefs about pain are more important than physical findings to predict long-term outcomes in people suffering from low back pain (Gifford et al., 2006; Chou and Shekelle, 2010).

Traditionally, psychosocial risk factors are seen as preexisting patient traits that clinicians are asked to evaluate and modify (Poitras et al., 2008; Deyo et al., 1992). Rarely however does it come to the clinician's mind that his own attitude and interventions can create or perpetuate pathological misbeliefs and maladaptive coping behaviors. In the present article, we describe the case of a 17 year-old female who complained of neck and back pain and whose condition improved drastically when a physiotherapist reassured her about the findings of the physical exam and brought her attention away from the abnormalities initially identified.

\section{Patient}

The patient, VT, was a 17 year-old female who complained of neck and back pain following a motor vehicle accident. She was referred to a physiotherapy clinic where she was treated during seven weeks with manual therapy, range of motion exercises and electrotherapeutic modalities. VT then moved in a nearby city and was transferred to another clinic to pursue her rehabilitation.

During her initial visit at the second physiotherapy clinic, VT rated her neck and back pain at 75 on a $0-100$ numerical pain scale $(0=$ no pain; $100=$ worst pain imaginable $)$. 
The pain was worse upon waking up, was increased by active movements of the cervical and thoracic spine, and relieved by rest and heat. Since the accident, VT believed her condition was slightly worse. She was particularly concerned about the findings of the previous physiotherapist who had identified four misaligned vertebrae in her back.

Postural evaluation revealed protracted cervical spine and shoulders, and increased lordosis of the lumbar spine. Active range of motion (ROM) of the cervical and thoracic spine was complete and non-painful, except for right cervical rotation which was reduced by $50 \%$ and reproduced her typical pain. Shoulder girdle movements were complete and non-painful. Cervical and thoracic compression and traction did not provoke nor relieve her symptoms. Postero-anterior pressure on the spinous and transverse processes of the cervical and thoracic spine showed normal mobility and did not elicit her typical pain. There was a slight left rotation of the vertebras T2-T4 which were judge non-clinically significant (Kouwenhoven et al., 2006). The neurological evaluation (reflexes, myotomes and dermatomes) was normal. A score of 25 on the McGill Pain Questionnaire Pain Rating Index (MPQ-PRI) (Melzack, 1975) was obtained. Perceived disability, measured with the Pain Disability Index (PDI) (Tait et al., 1990), and catastrophic thinking, measured with the Pain Catastrophizing Scale (PCS) (Sullivan et al., 1995), yielded total scores of 36 and 37 respectively, suggesting that the patient was at high risk for developing chronic pain and disability (Neubauer et al., 2006; Adams et al., 2007) .

\section{Intervention}

The physiotherapy interventions (unidisciplinary treatments) were prescribed and provided by a certified physiotherapist. Treatments were articulated around an active approach with emphasis on aerobic exercises (high intensity walking on a treadmill, upper 
extremity cycling at a moderate pace on an ergocycle), postural exercises (gentle scapular and cervical retraction) and neck mobility exercises (active ROM in rotation). Education and reassurance was also extensively used in order to explain the condition in fear-reducing terms. For example, during the assessment of her vertebral mobility using manual therapy techniques, VT was told that the mobility of each vertebra assessed in her back and neck was normal, and that the alignment of her vertebras was within the normal limit and did not contribute to her symptoms.

At the next visit two days later, VT reported important improvements in her back and neck, and stated that she was reassured to know that the four vertebrae in her back were properly aligned. VT was seen three other times at the clinic (2, 5 and 10 days after the initial visit). At her last visit, she reported no neck or back pain except during prolonged standing and sitting periods. The MPQ-PRI was now at 7. The next day, VT phoned the physiotherapy clinic to cancel her appointments. When contacted by her physiotherapist, she stated that her condition improved to the point where she judged that physiotherapy treatments were no longer needed.

VT was seen one last time 8 months after the initial evaluation. During this last visit, VT stated that the pain in her neck and back had completely disappeared. She did not report any neck or back pain since her last visit and did not seek the services of any other health professionals. Physical examination showed that cervical and thoracic range of motion were complete and pain free. Postural evaluation still revealed protracted cervical spine and shoulders, and increased lumbar lordosis. Both the MPQ-PRI and PDI yielded a score of 0 .

\section{Discussion}


Probably because of their strong biomedical background, a lot of efforts are generally made by physiotherapists to identify and treat the presumed source of pain. Without discarding the influence of biological factors, physiotherapist and other healthcare professionals must remember that pain perception is a subjective experience influenced both by biological and psychological factors (Fillingim, 2000). Placing too much emphasis on physical abnormalities can induce a negative self-perception of health and lead to fear avoidance and pain catastrophizing behaviors, a situation that may predispose individuals to chronic pain (Ash et al., 2008; Flynn et al., 2011).

Even though it might be tempting to suggest that the changes noted by VT are attributable to simple reassurance, we must remember that other factors (e.g., use of an active rather than passive approach, change of neighborhood and working environment) probably also played a significant role. Still, we propose that the improvements noted by VT are largely attributable to the comforting attitude demonstrated by the second physiotherapist who corrected VT's misbeliefs about pain and reassured her concerns. This hypothesis is supported (1) by the patient herself who stated that she was reassured to know that the vertebrae in her back were properly aligned and (2) by the rapidity with which the changes occurred (i.e., reduction of pain from 75 to 0 in less than two weeks). These rapid changes contrast with the slight exacerbation noted during the first seven weeks of treatment. It is also of particular interest to note that the improvements in pain noted by VT occurred despite the persistent postural abnormalities noted at follow-up, again arguing against the existence of a simple causal relationship between physical abnormalities and pain.

We argue that the emphasis placed by the former physiotherapist on the vertebral 
misalignment probably contributed to the maintenance of VT's pain. Although the negative impact that clinicians can have on patients' conditions have been discussed in a previous paper (Benedetti et al., 2007) and that experimental data support such negative influence (see for instance Goffaux et al., 2007), the present case report is, to our knowledge, the first article to illustrate how these concepts can translate in clinical practice.

\section{Acknowledgements}

The authors would like to thank Éric Bouchard and François Auray for their clinical support, as well as Joël Charlebois for his thoughtful comments on the manuscript. 


\title{
Figure Legend
}

1. Reproduction of the McGill Pain Questionnaire of VT obtained at the initial visit.

\section{MGGILL PAIN RUESTIONNAIRE}

\author{
Client No:: $V T$ Age: 17 Sex: $M\left(\_\right) F(\square)$ Date:
}

Please place a check mark ( $\checkmark$ ) beside each word that describes the pain you typically experience. If you experience more than one type of pain, use check marks to describe the pain that is most problematic.

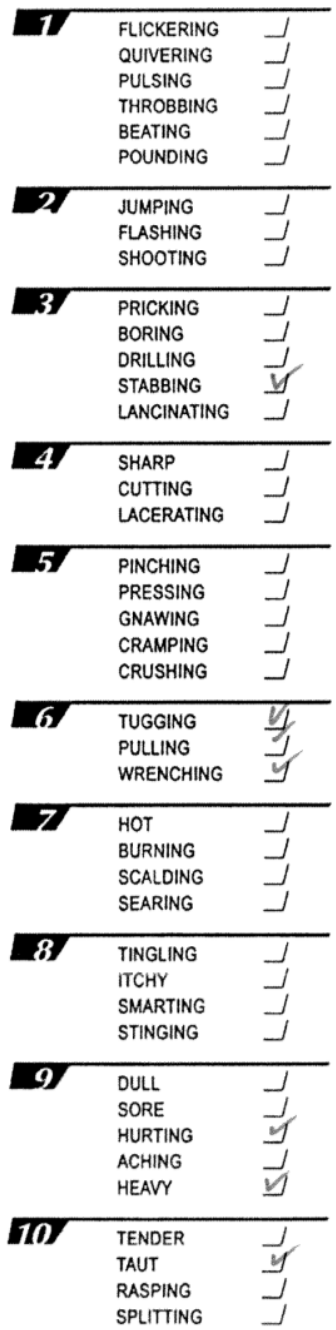
IN THE DRAWING BELOW, PLEASE 'SHADE IN'
THE AREAS THAT CORRESPOND TO WHERE YOU FEEL PAIN.
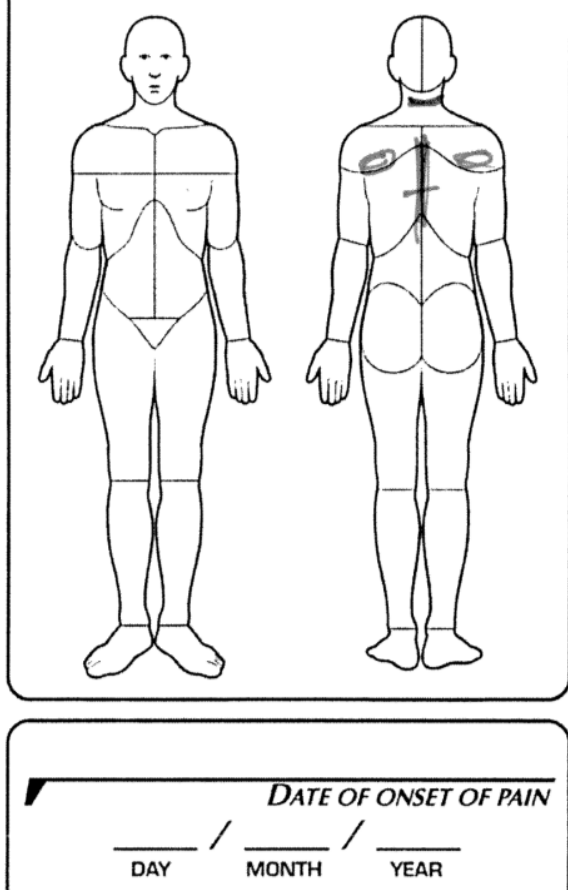

PPI

PLEASE CIRCLE A NUMBER TO INDICATE HOW MUCH PAIN YOU ARE EXPERIENCING PRESENTIY

$\begin{array}{llllllllllll}0 & 1 & 2 & 3 & 4 & 5 & 6 & 7 & 8 & 9 & 10\end{array}$ NOPAIN MILD DISCOMFORTING DISTRESSING HORRIBLE EXCRUCIATING

\begin{tabular}{|c|c|c|}
\hline 11 & $\begin{array}{l}\text { TIRING } \\
\text { EXHAUSTING }\end{array}$ & D \\
\hline 12 & $\begin{array}{l}\text { SICKENING } \\
\text { SUFFOCATING }\end{array}$ & $J$ \\
\hline 13 & $\begin{array}{l}\text { FEARFUL } \\
\text { FRIGHTFUL } \\
\text { TERRIFYING }\end{array}$ & $J$ \\
\hline 14 & $\begin{array}{l}\text { PUNISHING } \\
\text { GRUELLING } \\
\text { CRUEL } \\
\text { VICIOUS } \\
\text { KILLING }\end{array}$ & $\begin{array}{l}J \\
J \\
J \\
J \\
J\end{array}$ \\
\hline 15 & $\begin{array}{l}\text { WRETCHED } \\
\text { BLINOING }\end{array}$ & y \\
\hline 16 & $\begin{array}{l}\text { ANNOYING } \\
\text { TROUBLESOME } \\
\text { MISERABLE } \\
\text { INTENSE } \\
\text { UNBEARABLE }\end{array}$ & $\begin{array}{l}J \\
J \\
J \\
J\end{array}$ \\
\hline 17 & $\begin{array}{l}\text { SPREADING } \\
\text { RADIATING } \\
\text { PENETRATING } \\
\text { PIERCING }\end{array}$ & $\begin{array}{l}J \\
J \\
J\end{array}$ \\
\hline 18 & $\begin{array}{l}\text { TIGHT } \\
\text { NUMB } \\
\text { DRAWING } \\
\text { SQUEEZING } \\
\text { TEARING }\end{array}$ & $\begin{array}{l}J \\
J \\
J \\
J \\
J\end{array}$ \\
\hline 19 & $\begin{array}{l}\text { COOL } \\
\text { COLD } \\
\text { FREEZING }\end{array}$ & $\begin{array}{l}J \\
J\end{array}$ \\
\hline 20 & $\begin{array}{l}\text { NAGGING } \\
\text { NAUSEATING } \\
\text { AGONIZING } \\
\text { DREADFUL } \\
\text { TORTURING }\end{array}$ & $\begin{array}{l}J \\
J \\
J \\
J\end{array}$ \\
\hline \multicolumn{3}{|c|}{ CURRENT MEDICATION FOR PAII } \\
\hline
\end{tabular}




\section{References}

Adams H, Ellis T, Stanish WD, Sullivan MJ (2007). Psychosocial factors related to return to work following rehabilitation of whiplash injuries. J Occup Rehabil 17: 305-315.

Ash LM, Modic MT, Obuchowski NA, Ross JS, Brant-Zawadzki MN, Grooff PN (2008). Effects of diagnostic information, per se, on patient outcomes in acute radiculopathy and low back pain. $A J N R$ 29: 1098-1103.

Benedetti F, Lanotte M, Lopiano L, Colloca L (2007). When words are painful: unraveling the mechanisms of the nocebo effect. Neuroscience 147: 260-271.

Chou $\mathrm{R} \&$ Shekelle P (2010). Will this patient develop persistent disabling low back pain? JAMA 303: 1295-1302.

Deyo RA, Rainville J, Kent DL (1992). What can the history and physical examination tell us about low back pain? JAMA 268: 760-765.

Fillingim RB (2000). Sex, gender and pain: a biopsychosocial framework. In Sex, Gender, and Pain. Seattle: IASP Press; pp. 1-6.

Flynn TW, Smith B, Chou R (2011). Appropriate use of diagnostic imaging in low back pain: a reminder that unnecessary imaging may do as much harm as good. J Orthop Sports Phys Ther 41: 838-846.

Gifford L, Thacker M, Jones MA (2006). Physiotherapy and Pain. In Wall and Melzack's Textbook of Pain. China: Elsevier Churchill Livingstone; pp. 603-617.

Goffaux P, Redmond WJ, Rainville P, Marchand S (2007). Descending analgesia--when the spine echoes what the brain expects. Pain 130: 137-143.

Kouwenhoven JW, Vincken KL, Bartels LW, Castelein RM (2006). Analysis of preexistent vertebral rotation in the normal spine. Spine 31: 1467-1472.

Melzack R (1975). The McGill Pain Questionnaire: major properties and scoring methods. Pain 1: 277-299.

Neubauer E, Junge A, Pirron P, Seemann H, Schiltenwolf M (2006). HKF-R 10 - screening for predicting chronicity in acute low back pain (LBP): a prospective clinical trial. Eur J Pain 10: 559-566.

Poitras S, Rossignol M, Dionne C, Tousignant M, Truchon M, Arsenault B, Allard P, Cote M, Neveu A (2008). An interdisciplinary clinical practice model for the management of low-back pain in primary care: the CLIP project. BMC Musculoskelet Disord 9: 54.

Sullivan MJ, Bishop SR, Pivik J (1995). The Pain Catastrophizing Scale: Development and Validation. Psychol Assess 7: 524-532. 
Tait RC, Chibnall JT, Krause S (1990). The Pain Disability Index: psychometric properties. Pain 40: 171-182. 